\title{
Chirality Induction in Cyclopolymerization X. Structural Effect of Three D-Mannitol Templates in the Cyclocopolymerization of Bis(4-vinylbenzoate) with Styrene
}

\author{
Takahiro Uesaka, Yui Sugiura, Makoto Obata, Atsushi Narumi, \\ Kazuaki YoKota, ${ }^{\dagger}$ and Toyoji KAKUCHI* \\ Division of Molecular Chemistry, Graduate School of Engineering, Hokkaido University, \\ Sapporo 060-8628, Japan \\ * Division of Bioscience, Graduate School of Environmental Earth Science, Hokkaido University, \\ Sapporo 060 0810, Japan
}

(Received October 12, 1998)

\begin{abstract}
Three chiral diols, 1,2:5,6-di-O-isopropylidene-, 1,2:4,6-di- $O$-isopropylidene-, and 1,2:4,5-di- $O$-isopropylidene-D-mannitol (a, b, and $\mathbf{c}$, respectively) were used as template for chirality induction in the cyclocopolymerizations of bis(4-vinylbenzoate) monomers (1a, $\mathbf{1 b}$, and $\mathbf{1 c}$ ) with styrene. The chirality of polymers $\mathbf{3 a}$ and $\mathbf{3 b}$ was opposite to that of monomers $\mathbf{1 a}$ and $\mathbf{1 b}$ on their $\mathrm{CD}$ spectra. In contrast, the chirality of polymer $\mathbf{3 c}$ was the same as that of monomer $\mathbf{1 c}$. The efficiency of template on the chirality induction decreased in the order of $\mathbf{b}>\mathbf{a}>\mathbf{c}$. The efficiency is lower for template $\mathbf{b}$ than the corresponding acyclic template $\mathbf{e}$, though being higher for templates $\mathbf{a}$ and $\mathbf{c}$ than the acyclic templates $\mathbf{d}$ and $\mathbf{i}$, respectively. These characters of the mannitol templates were discussed on the basis of the most suitable conformer in the monomers. KEY WORDS Asymmetric Polymerization / Chirality Induction/Cyclopolymerization / Chiral Template / Exciton Chirality Method/
\end{abstract}

A considerable number of studies have been made on preparing optically active polymers by asymmetric polymerization. ${ }^{1}$ Cyclocopolymerization, which involves copolymerization of a chiral divinyl monomer with an achiral monovinyl monomer, is a useful method for the synthesis of an optically active polymer whose chirality is due to chiral carbons in the main chain. ${ }^{2}$ The bis(4vinylbenzoate) monomers derived from chiral diols, such as methyl $4,6-O$-isopropylidene- $\alpha$-D-glucopyranoside, ${ }^{3}$ 1,2:5,6-di- $O$-isopropylidene-D-mannitol, ${ }^{4}$ and 2,3-Oisopropylidene-L-threitol, ${ }^{5}$ were well suitable for this purpose. The absolute configuration of the monomers and the resulting copolymers can be determined by the exciton chirality method. ${ }^{6}$ The acyclic simple diols $(\mathbf{d}-\mathbf{i}$ in Scheme 1) clarified the structural effect, which concerns the distance between the two hydroxyl groups and the number of the chiral centers in the template, on the efficiency of chirality induction. ${ }^{7}$ The increase of the order of efficiency for each template with one chiral center and two centers is as follows: 1,2-diol $<1,4$-diol $<1,3-$ diol. Template e with two chiral centers almost doubled the efficiency in comparison to template $\mathbf{h}$ with one chiral center. The chirality induction of monomers $\mathbf{1 d}-\mathbf{f}$ was characterized by means of a semiempirical molecular orbital calculation. ${ }^{8}$

Carbohydrate is one of the convenient sources for the preparation of chiral diols as the template. The molecular symmetry effect on the chirality induction was discussed using $C_{2}$ symmetric 1,2:5,6-di- $O$-isopropylidene-Dmannitol, D-iditol, and $C_{1}$ symmetric D-glucitol in the previous papers. ${ }^{4,9} \mathrm{D}$-Mannitol, which is a useful source of chiral building block in organic synthesis, can be converted into 1,2:5,6-, 1,2:4,6-, and 1,2:4,5-di- $O$ isopropylidene derivatives corresponding to $1,2-1,3-$, and 1,4-diol templates $(\mathbf{a}, \mathbf{b}$, and $\mathbf{c})$, respectively. In this paper, the cyclocopolymerizations of $1,2: 4,6$-di- $O$-isopropylidene-3,5- and 1,2:4,5-di- $O$-isopropylidene-3,6-bis- $O$-(4vinylbenzoyl)-D-mannitol (1b and 1c) with styrene, in addition to the previous result of $1,2: 5,6$-di- $O$-isopropylidene-3,4-bis- $O$-(4-vinylbenzoyl)-D-mannitol (1a), ${ }^{4}$ examined the template effect on chirality induction. The polymerization system of monomer 1c was different in chiroptical property from the general system containing monomers 1a and $\mathbf{1 b}$. Modifications of the templates by dioxolane or dioxane moieties produced a positive effect on monomers 1a and 1c, but a negative effect on monomer $\mathbf{1 b}$ by comparison of the corresponding monomers with the acyclic diol templates. The influence of the modifications was discussed on the basis of the conformation of the monomers.

\section{EXPERIMENTAL}

\section{Measurements}

${ }^{1} \mathrm{H}$ and ${ }^{13} \mathrm{C}$ NMR spectra were recorded using a JEOL JNM-EX270 and a JNM-A400II instrument. Quantitative ${ }^{13} \mathrm{C}$ NMR spectra were obtained at $30^{\circ} \mathrm{C}$ in $\mathrm{CDCl}_{3}$ solvent $\left(100 \mathrm{mg} \mathrm{ml}^{-1}\right.$; pulse width, $45^{\circ}$; delay time, $7.0 \mathrm{~s}$; inverse gated decoupling). IR spectra were recorded using a Perkin-Elmer Paragon 1000 and UV spectra were recorded on a JASCO 660 UV/VIS spectrometer. The molecular weights of copolymers were determined by gel permeation chromatography (GPC) in tetrahydrofuran on a JASCO GPC-900 system equipped with three polystyrene gel columns (Shodex KF-804L). The numberaverage molecular weights $\left(M_{n}\right)$ were calculated on the basis of a polystyrene calibration. Optical rotations were measured with a JASCO DIP-1000 digital polarimeter. $\mathrm{CD}$ spectra were measured at $23^{\circ} \mathrm{C}$ in hexafluoroisopropyl alcohol (HFIP) with a $5 \mathrm{~mm}$ path length cell

† To whom all correspondence should be addressed (Tel and Fax: +81-11-706-6602, e-mail: yokota(a poly.eng.hokudai.ac.jp). 


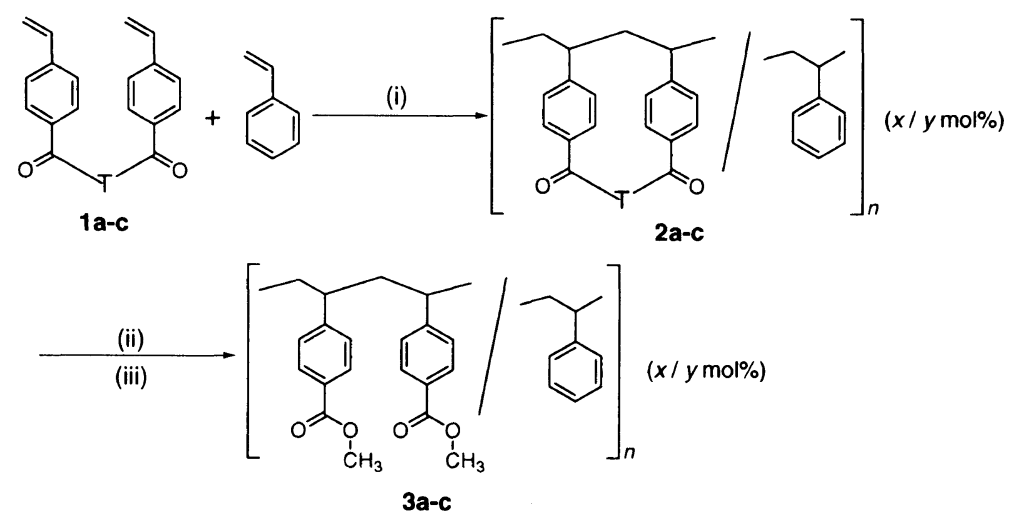

$\mathrm{T}$ :
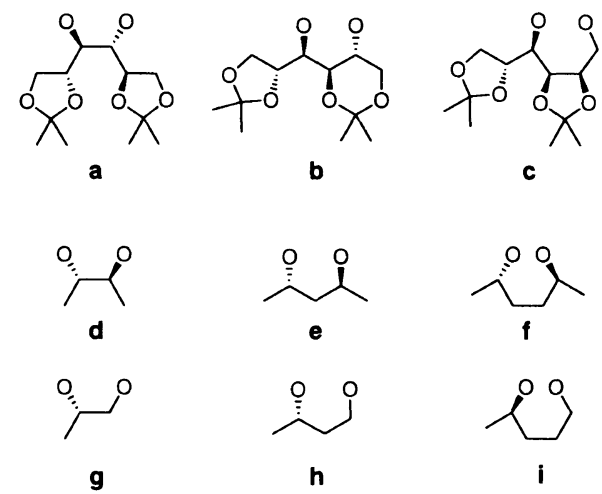

Conditions: (i) AIBN, toluene, $60^{\circ} \mathrm{C}$; (ii) $\mathrm{KOH}, \mathrm{MeOH}$, reflux; (iii) $\mathrm{CH}_{2} \mathrm{~N}_{2}$, ether, rt.

Scheme 1.

using a JASCO J-720 spectropolarimeter.

\section{Materials}

Toluene (dehydrated) was purchased from Kanto Chemical Co. and used without further purification. $1,2: 4,5$-Di- $O$-isopropylidene-D-mannitol was purchased from Aldrich. Pyridine was dried over $\mathrm{CaH}_{2}$ and distilled prior to use. 2,2'-Azobis(2-methylpropionitrile) (AIBN) was recrystallized from methanol. Hexafluoroisopropyl alcohol was obtained from the Central Glass Co. and used without further purification.

\section{1,2:4,6-Di-O-isopropylidene-3,5-bis-O-(4-vinylbenzoyl)- D-mannitol (1) \\ A solution of $1,2: 4,6$-di- $O$-isopropylidene-D-manni-} $\operatorname{tol}^{10}(3.0 \mathrm{~g}, 11 \mathrm{mmol})$ in dry pyridine $(75 \mathrm{ml})$ was cooled to $5^{\circ} \mathrm{C}$. To this solution, 4-vinylbenzoyl chloride ${ }^{11}(5.5 \mathrm{~g}$, $33 \mathrm{mmol}$ ) was added dropwise over a 10 -min period. The reaction mixture was stirred for $12 \mathrm{~h}$ at room temperature. The mixture was cooled to $0^{\circ} \mathrm{C}$ in an ice bath, and water $(75 \mathrm{ml})$ was then added. The resulting mixture was stirred for an additional hour, and then the solution was extracted with three portions of ether $(100 \mathrm{ml})$. The extract was washed with three portions of $2 \mathrm{M}$ hydrochloric acid $(100 \mathrm{ml}), 2 \mathrm{M}$ aqueous $\mathrm{NaOH}(100 \mathrm{ml})$, and water $(100 \mathrm{ml})$. The organic layer was dried over $\mathrm{MgSO}_{4}$ and the solvent was evaporated under reduced pressure. The residue was purified by squat column chromatography on alumina (MERCK Aluminium oxide 90) with ether, followed by flash column chromatography using silica gel (MERCK Silica gel 60) with hexane-ethyl acetate $(4: 1, \mathrm{v} / \mathrm{v})$ to give $5.1 \mathrm{~g}(9.7 \mathrm{mmol}, 88 \%)$ of $\mathbf{1 b}$ as a white powder. $[\alpha]_{\mathrm{D}}^{25}=-164^{\circ},[\alpha]_{435}^{25}=-434^{\circ}(c 1.0$, $\left.\mathrm{CHCl}_{3}\right) .{ }^{1} \mathrm{H} \mathrm{NMR}\left(400 \mathrm{MHz}, \mathrm{CDCl}_{3}\right): \delta(\mathrm{ppm})=7.99$ (d, $\left.{ }^{3} J=8.3 \mathrm{~Hz}, 2 \mathrm{H}, \mathrm{Ar}\right), 7.96\left(\mathrm{~d},{ }^{3} J=8.3 \mathrm{~Hz}, 2 \mathrm{H}, \mathrm{Ar}\right)$, $7.45\left(\mathrm{~d},{ }^{3} J=8.5 \mathrm{~Hz}, 4 \mathrm{H}, \mathrm{Ar}\right), 6.75\left(\mathrm{dd},{ }^{3} J_{\text {trans }}=17.6 \mathrm{~Hz}\right.$, $\left.{ }^{3} J_{\text {cis }}=10.7 \mathrm{~Hz}, 2 \mathrm{H}, \mathrm{CH}=\right), 5.86\left(\mathrm{dd},{ }^{3} J_{\text {trans }}=17.7 \mathrm{~Hz}\right.$, $\left.{ }^{2} J_{\mathrm{gem}}=2.3 \mathrm{~Hz}, 2 \mathrm{H},=\mathrm{CH}_{2}\right), 5.57-5.59(\mathrm{~m}, 1 \mathrm{H}, \mathrm{CH})$, $5.39\left(\mathrm{dd},{ }^{3} J_{\text {cis }}=10.8 \mathrm{~Hz},{ }^{2} J_{\text {gem }}=1.8 \mathrm{~Hz}, 2 \mathrm{H},=\mathrm{CH}_{2}\right)$, $4.904 .96(\mathrm{~m}, 1 \mathrm{H}, \mathrm{CH}), 4.35-4.45(\mathrm{~m}, 2 \mathrm{H}, \mathrm{CH})$, $4.14-4.18\left(\mathrm{~m}, 1 \mathrm{H}, \mathrm{CH}_{2}\right), 4.02-4.04\left(\mathrm{~m}, 2 \mathrm{H}, \mathrm{CH}_{2}\right)$, $3.75-3.79\left(\mathrm{~m}, 1 \mathrm{H}, \mathrm{CH}_{2}\right), 1.54\left(\mathrm{~s}, 3 \mathrm{H}, \mathrm{CH}_{3}\right), 1.46(\mathrm{~s}, 3 \mathrm{H}$, $\left.\mathrm{CH}_{3}\right), 1.33\left(\mathrm{~s}, 3 \mathrm{H}, \mathrm{CH}_{3}\right), 1.32\left(\mathrm{~s}, 3 \mathrm{H}, \mathrm{CH}_{3}\right) .{ }^{13} \mathrm{C} \mathrm{NMR}$ $\left(100 \mathrm{MHz}, \mathrm{CDCl}_{3}\right): \delta(\mathrm{ppm})=165.4,165.3(\mathrm{C}=\mathrm{O}), 142.3$, $142.3,130.3,130.1,128.7,128.7,126.2,126.1$ (Ar), 136.0 $(=\mathrm{CH}), 116.7\left(=\mathrm{CH}_{2}\right), 109.0,99.9(\mathrm{C}), 74.6,70.7,69.9$, $66.4(\mathrm{CH}), 66.2,62.3\left(\mathrm{CH}_{2}\right), 27.0,26.6,25.5,20.5\left(\mathrm{CH}_{3}\right)$. Anal. Calcd for $\mathrm{C}_{30} \mathrm{H}_{34} \mathrm{O}_{8}$ (522.6): C 68.95; H 6.56 . Found: C 68.34; H 6.58.

\section{1,2:4,5-Di-O-isopropylidene-3,6-bis-O-(4-vinylbenzoyl)- D-mannitol (1c)}

The procedure for $\mathbf{1 b}$ was applied to $1,2: 4,5$-di- $O$ isopropylidene-D-mannitol $(5.0 \mathrm{~g}, 19 \mathrm{mmol})$ and 4-vinylbenzoyl chloride $(7.9 \mathrm{~g}, 48 \mathrm{mmol})$. The crude product was purified by flash column chromatography on silica gel (MERCK Silica gel 60) with hexane-ether $(2: 1, \mathrm{v} / \mathrm{v})$, followed by recrystallization from hexane to give $6.5 \mathrm{~g}$ $(13 \mathrm{mmol}, 66 \%)$ of $1 \mathrm{c}$ as a white crystal. $[\alpha]_{\mathrm{D}}^{25}=-66^{\circ}$, $\left.[\alpha]_{435}^{25}=-170^{\circ}(c) 1.0, \mathrm{CHCl}_{3}\right) .{ }^{1} \mathrm{H}$ NMR $(400 \mathrm{MHz}$, $\left.\mathrm{CDCl}_{3}\right): \delta(\mathrm{ppm})=8.03\left(\mathrm{~d},{ }^{3} J=8.3 \mathrm{~Hz}, 2 \mathrm{H}, \mathrm{Ar}\right), 7.99(\mathrm{~d}$, $\left.{ }^{3} J=8.3 \mathrm{~Hz}, 2 \mathrm{H}, \mathrm{Ar}\right), 7.48\left(\mathrm{~d},{ }^{3} J=8.3 \mathrm{~Hz}, 2 \mathrm{H}, \mathrm{Ar}\right), 7.44$ $\left(\mathrm{d},{ }^{3} J=8.3 \mathrm{~Hz}, 2 \mathrm{H}, \mathrm{Ar}\right), 6.75\left(\mathrm{dd},{ }^{3} J_{\text {trans }}=17.6 \mathrm{~Hz}\right.$, $\left.{ }^{3} J_{\text {cis }}=11.0 \mathrm{~Hz}, 1 \mathrm{H},-\mathrm{CH}=\right), 6.74\left(\mathrm{dd},{ }^{3} J_{\text {trans }}=17.6 \mathrm{~Hz}\right.$, 
Table I. Copolymerizations of $\mathbf{1 b}$ and $\mathbf{1 c}\left(\mathrm{M}_{1}\right)$ with styrene $\left(\mathrm{M}_{2}\right)$ and synthesis of poly[(methyl 4-vinylbenzoate)-co-styrene $](3)^{\mathrm{a}}$

\begin{tabular}{|c|c|c|c|c|c|c|c|c|c|}
\hline \multirow{3}{*}{ Monomer } & \multirow{3}{*}{$\begin{array}{l}\text { Mole fraction } \\
\text { of } M_{1} \text { in feed }\end{array}$} & \multirow{3}{*}{$\frac{\text { Time }}{h}$} & \multirow{3}{*}{$\frac{\text { Yield }}{\%}$} & \multirow{3}{*}{$\begin{array}{c}\text { Mole fraction of } \\
\mathrm{M}_{1} \text { in } \\
\text { copolymer }^{\mathrm{c}}\end{array}$} & \multirow{3}{*}{$\begin{array}{l}M_{n} \times 10^{-3} \\
\left(M_{w} / M_{n}\right)^{\mathrm{d}}\end{array}$} & \multirow{3}{*}{$\frac{[\alpha]_{435}{ }^{\mathrm{e}}}{\operatorname{deg}}$} & \multicolumn{3}{|c|}{ Synthesis of $\mathbf{3}^{\mathbf{b}}$} \\
\hline & & & & & & & Yield & $M \times 10^{-3}$ & {$[\alpha]_{435}{ }^{\mathrm{e}}$} \\
\hline & & & & & & & $\%$ & $\left(M_{w} / M_{n}\right)^{\mathrm{d}}$ & $\operatorname{deg}$ \\
\hline \multirow[t]{5}{*}{$1 \mathbf{b}$} & 0.10 & 13.3 & 25 & 0.29 & $4.7(1.43)$ & -188 & 55 & $4.3(1.35)$ & +49.2 \\
\hline & 0.30 & 3.5 & 25 & 0.59 & $11.5(1.82)$ & -256 & 66 & $7.8(1.87)$ & +33.3 \\
\hline & 0.49 & 2.7 & 17 & 0.63 & 18.7 (1.99) & -245 & 40 & $15.3(1.83)$ & +18.6 \\
\hline & 0.68 & 1.5 & 17 & 0.77 & $29.8(2.05)$ & -288 & 53 & $21.8(2.53)$ & +9.0 \\
\hline & 0.85 & 0.8 & 22 & 0.95 & $22.5(2.24)$ & -286 & 52 & $18.3(1.89)$ & +4.8 \\
\hline \multirow[t]{5}{*}{ 1c } & 0.10 & 16.7 & 30 & 0.21 & $3.9(3.60)$ & +107 & 79 & $4.3(2.79)$ & -11.4 \\
\hline & 0.30 & 9.5 & 15 & 0.51 & 7.3 (1.99) & +95 & 91 & $6.6(1.69)$ & -6.7 \\
\hline & 0.40 & 11.5 & 20 & 0.60 & $8.2(2.52)$ & +79 & 96 & $6.8(1.72)$ & -4.9 \\
\hline & 0.70 & 3.3 & 29 & 0.71 & $16.8(4.73)$ & +75 & 53 & $12.3(2.68)$ & -2.1 \\
\hline & 0.90 & 1.0 & 26 & 0.97 & $24.8(6.00)$ & +58 & 52 & $30.0(2.16)$ & -0.5 \\
\hline
\end{tabular}

${ }^{a}$ Solvent, toluene; initiator, AIBN; temperature, $60^{\circ} \mathrm{C} ;\left[\mathrm{M}_{1}+\mathrm{M}_{2}\right]=0.1 \mathrm{~mol} \mathrm{~L}^{-1}$; [AIBN] $=6 \mathrm{mmol} \mathrm{L}^{-1}$. ${ }^{\mathrm{b}}$ Prepared from copolymer 2 through hydrolysis using $\mathrm{KOH}$ in aqueous $\mathrm{MeOH}$ for $50 \mathrm{~h}$ under reflux and treatment with diazomethane in benzene-ether. ${ }^{\mathrm{c}}$ Determined by ${ }^{13} \mathrm{C}$ and ${ }^{1} \mathrm{H}$ NMR spectra. ${ }^{\mathrm{d}}$ Determined by GPC in THF using polystyrene standards. ${ }^{\mathrm{e}} \mathrm{Measured} \mathrm{in} \mathrm{CHCl}_{3}$ at $25^{\circ} \mathrm{C}(c=1.0)$.

$\left.{ }^{3} J_{\text {cis }}=11.0 \mathrm{~Hz}, 1 \mathrm{H},-\mathrm{CH}=\right), 5.87\left(\mathrm{dd},{ }^{3} J_{\text {trans }}=17.6 \mathrm{~Hz}\right.$ $\left.{ }^{2} J_{\text {gem }}=0.7 \mathrm{~Hz}, 1 \mathrm{H},=\mathrm{CH}_{2}\right), 5.86\left(\mathrm{dd},{ }^{3} J_{\text {trans }}=17.6 \mathrm{~Hz}\right.$, $\left.{ }^{2} J_{\text {gem }}=0.5 \mathrm{~Hz}, 1 \mathrm{H},=\mathrm{CH}_{2}\right), 5.56\left(\mathrm{dd},{ }^{3} \mathrm{~J}=2.20 \mathrm{~Hz},{ }^{3} \mathrm{~J}=\right.$ $6.10,1 \mathrm{H}, \mathrm{CH}), 5.41-5.37\left(\mathrm{~m}, 2 \mathrm{H},=\mathrm{CH}_{2}\right), 4.60-4.36$ $\left(\mathrm{m}, 5 \mathrm{H}, \mathrm{CH}, \mathrm{CH}_{2}\right), 4.07\left(\mathrm{~d}, \mathrm{~J}=6.6 \mathrm{~Hz}, 2 \mathrm{H}, \mathrm{CH}_{2}\right), 1.59$ $\left(\mathrm{s}, 3 \mathrm{H}, \mathrm{CH}_{3}\right), 1.40\left(\mathrm{~s}, 3 \mathrm{H}, \mathrm{CH}_{3}\right), 1.36\left(\mathrm{~s}, 3 \mathrm{H}, \mathrm{CH}_{3}\right)$, $1.31\left(\mathrm{~s}, 3 \mathrm{H}, \mathrm{CH}_{3}\right) .{ }^{13} \mathrm{C} \mathrm{NMR}\left(100 \mathrm{MHz}, \mathrm{CDCl}_{3}\right): \delta$ $(\mathrm{ppm})=165.9,165.5(\mathrm{C}=\mathrm{O}), 142.4,142.1,130.2,130.1$, $128.8,126.2,126.0$ (Ar), 136.0, 136.0 (=CH), 116.8, 116.5 $\left(=\mathrm{CH}_{2}\right), 109.4,109.3(\mathrm{C}), 75.8,75.8,75.2,70.8(\mathrm{CH})$, 66.2, $63.2\left(\mathrm{CH}_{2}\right), 27.0,26.4,25.5,25.4\left(\mathrm{CH}_{3}\right)$. Anal. Calcd for $\mathrm{C}_{30} \mathrm{H}_{34} \mathrm{O}_{8}$ (522.6): $\mathrm{C} 68.95 ; \mathrm{H}$ 6.56. Found: $\mathrm{C} 69.03$; H 6.58 .

\section{Cyclocopolymerization}

The copolymerizations of $\mathbf{1 b}$ and $\mathbf{1 c}$ with styrene were carried out using AIBN in toluene at $60^{\circ} \mathrm{C}$. After an appropriate time, the polymerization mixture was poured into a large amount of methanol and the precipitate was filtered. The obtained polymer was purified by reprecipitation with chloroform-methanol and dried in vacuo. The composition of $\mathbf{2 b}-\mathbf{c}$ was determined from the areas of aromatic (122-132 ppm) and carbonyl (163-167 ppm) regions in the ${ }^{13} \mathrm{C}$ NMR spectrum of $2 \mathbf{b}-\mathbf{c}$.

Synthesis of poly [(methyl 4-vinylbenzoate)-co-styrene $]$ (3)

The procedures have been reported previously. ${ }^{3-5}$ The removal of the chiral template from 3 was carried out using $\mathrm{KOH}$ in aqueous $\mathrm{MeOH}$, and then the hydrolyzed copolymer was treated with diazomethane ${ }^{12}$ in benzeneether $(1: 1, \mathrm{v} / \mathrm{v})$.

\section{RESULTS AND DISCUSSION}

\section{Cyclocopolymerization}

Table I lists the results of the copolymerizations of $\mathbf{1 b}$ and 1c $\left(M_{1}\right)$ with styrene $\left(M_{2}\right)$ using AIBN in toluene at $60^{\circ} \mathrm{C}$. All of the polymerizations proceeded homogeneously, and the resulting copolymers ( $\mathbf{2 b}$ and $\mathbf{2 c}$ ) were soluble in common organic solvents such as chloroform and tetrahydrofuran. The number-average molecular weights of the copolymers tended to decrease with an

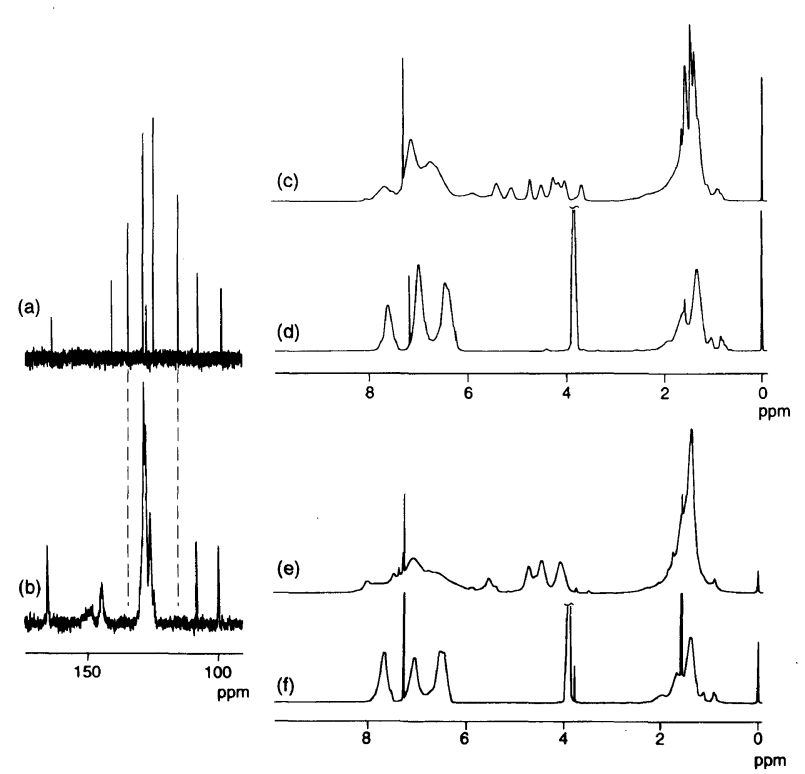

Figure 1. Expanded ${ }^{13} \mathrm{C}$ NMR spectra of (a) monomer $\mathbf{1 b}$ and (b) copolymer $\mathbf{2 b}(x / y=0.29 / 0.71)$, and ${ }^{1} \mathrm{H}$ NMR spectra of copolymers (c) 2b, (d) 3b $(x / y=0.29 / 0.71)$, (e) 2c $(x / y=0.21 / 0.79)$, and (f) 3c $(x / y=0.21 / 0.79)$, measured in $\mathrm{CDCl}_{3}$.

increase in $\mathrm{M}_{2}$ in the monomer feed and varied from 29800 and 24800 to 4700 and 3900 for $\mathbf{2 b}$ and $\mathbf{2 c}$, respectively. The variations correspond to those from 70 and 49 to 21 and 20 in the degrees of polymerization. The characteristic absorption due to the vinyl groups disappeared in the ${ }^{1} \mathrm{H}$ and ${ }^{13} \mathrm{C}$ NMR spectra of polymer 2b (Figure 1), and thus, monomer $\mathbf{1 b}$ was suggested to polymerize with complete cyclization in analogy with 1a. ${ }^{4}$ On the other hand, polymer $2 \mathrm{c}$ contained a small amount of residual double bonds and the extent of cyclization was $70-95 \%$, which increased with an increase of the $\mathrm{M}_{2}$ fraction in the feed. The comonomer simply acted as a diluent for the intramolecular cyclization of monomer $\mathbf{1 c}$, to say nothing of $\mathbf{1 b}$. The extended Kelen-Tüdös method ${ }^{13}$ gave the copolymerization parameters $r_{1}=2.22$ and $r_{2}=0.24$ for $\mathbf{1 b}$ and $r_{1}=3.14$ and $r_{2}=0.39$ for $1 c$, in contrast to those $r_{1}=2.35$ and 


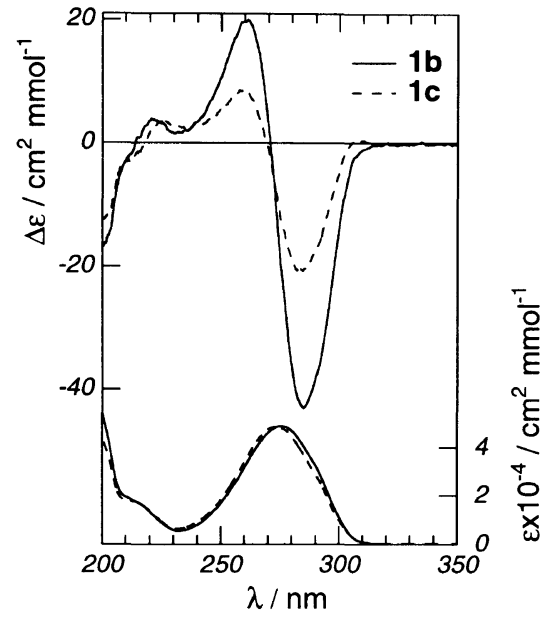

Figure 2. CD and UV spectra of monomers $\mathbf{1 b}$ and $\mathbf{1 c}$, measured in HFIP at $23^{\circ} \mathrm{C}$ using a path length of $5 \mathrm{~mm}$.

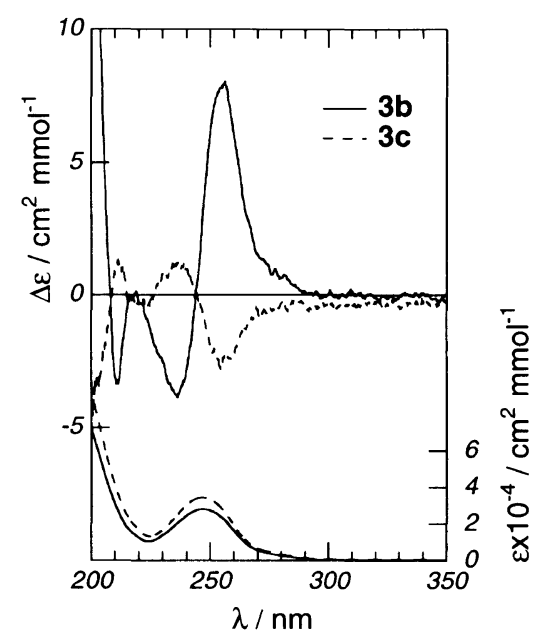

Figure 3. CD and UV spectra of copolymers $3 \mathbf{b}(x / y=0.29 / 0.71)$ and $3 c(x / y=0.21 / 0.79)$, measured in HFIP at $23^{\circ} \mathrm{C}$ using a path length of $5 \mathrm{~mm}$.

$r_{2}=0.40$ for $1 \mathbf{a}$.

\section{Template-Free Copolymers}

The specific rotation $\left([\alpha]_{435}^{25}, c 1.0, \mathrm{CHCl}_{3}\right)$ of the copolymers was changed in the range of $-188^{\circ}$ to $-288^{\circ}$ for $\mathbf{2} \mathbf{b}$ and $+58^{\circ}$ to $+107^{\circ}$ for $\mathbf{2 c}$. After removal of the chiral template and treatment with diazomethane, poly[(methyl 4-vinylbenzoate)-co-styrene]s (3) were optically active. The specific rotation $\left([\alpha]_{435}^{25}, c 1.0, \mathrm{CHCl}_{3}\right)$ increased with an increase in $\mathbf{M}_{2}$ in the monomer feed and varied from $+4.8^{\circ}$ to $+49.2^{\circ}$ for $3 \mathbf{b}$ and from $-0.5^{\circ}$ to $-11.4^{\circ}$ for $3 \mathrm{c}$ (Table I). The sign of these values is opposite to that for polymer $\mathbf{2}$ at every composition, which clearly indicates that a new source of chirality was generated in the main chain of copolymers 3 .

Figure 2 shows the CD and UV spectra of $\mathbf{1 b}$ and $\mathbf{1 c}$ in hexafluoroisopropanol. In the CD spectrum of $\mathbf{1 b}, \mathbf{a}$ negative first Cotton effect at $285 \mathrm{~nm}\left(\Delta \varepsilon=-43 \mathrm{~cm}^{2}\right.$ $\left.\mathrm{mmol}^{-1}\right)$ and a positive second Cotton effect at $261 \mathrm{~nm}$ $\left(\Delta \varepsilon=+20 \mathrm{~cm}^{2} \mathrm{mmol}^{-1}\right)$ are observed. The CD spectrum of 1c exhibits a negative Cotton effect at $285 \mathrm{~nm}(\Delta \varepsilon=$ $\left.-21 \mathrm{~cm}^{2} \mathrm{mmol}^{-1}\right)$ and a positive one at $258 \mathrm{~nm}(\Delta \varepsilon=$ $+8.6 \mathrm{~cm}^{2} \mathrm{mmol}^{-1}$ ) as well.

According to the $\mathrm{CD}$ exciton chirality method, ${ }^{6} \mathbf{1 b}$

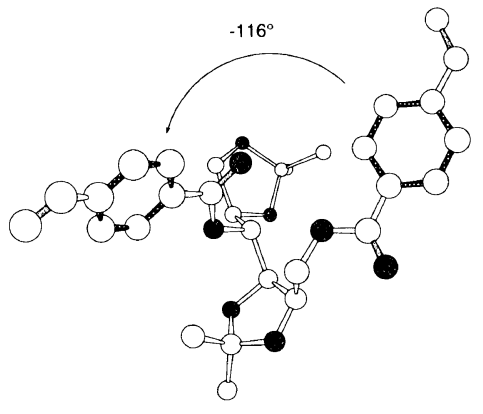

(a)

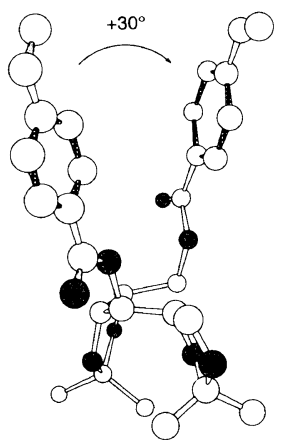

(b)
Figure 4. (A) Stable structure of monomer 1c and (b) its suitable structure for the intramolecular cyclization.

and 1c have a negative chirality and their benzoate chromophores, the two 4-vinylbenzoate groups, are twisted counter-clockwise. In the $C D$ spectrum of $\mathbf{3 b}$ $(x / y=0.29 / 0.71)$, a split Cotton effect with a positive first Cotton effect at $256 \mathrm{~nm}\left(\Delta \varepsilon=+8.0 \mathrm{~cm}^{2} \mathrm{mmol}^{-1}\right)$ and a negative second Cotton effect at $236 \mathrm{~nm}\left(\Delta \varepsilon=-3.9 \mathrm{~cm}^{2}\right.$ $\mathrm{mmol}^{-1}$ ) are observed (Figure 3$)$. On the other hand, the $\mathrm{CD}$ spectrum of polymer $3 \mathbf{c}(x / y=0.21 / 0.79)$ showed a negative first Cotton effect at $254 \mathrm{~nm}\left(\Delta \varepsilon=-2.8 \mathrm{~cm}^{2}\right.$ $\left.\mathrm{mmol}^{-1}\right)$ and a positive second Cotton effect at $236 \mathrm{~nm}$ $\left(\Delta \varepsilon=+1.2 \mathrm{~cm}^{2} \mathrm{mmol}^{-1}\right)$. Polymer $\mathbf{3 b}$ possesses a positive chirality in which the two benzoyl groups are twisted clockwise, while polymer $3 \mathbf{c}$ possesses a negative chirality. The absolute configuration of the main chain carbons originated in the chiral $M_{1}$ unit, therefore, is determined to be an $S, S$-racemo for $\mathbf{3 b}$ and an $R, R$-racemo for $\mathbf{3 c}$.

During the cyclocopolymerization, the template having an $R, R$-configuration generally induced an $S, S$-racemo configuration in the main chain and vice versa. The chirality of polymer $\mathbf{3}$, thus, was opposite to that of monomer 1 on their CD spectra. Polymer 3b falls under the category together with $3 \mathbf{a}^{4}$ In contrast, the chirality of polymer 3c was the same as that of monomer 1c. The monomer having a high tendency for intramolecular cyclization should have a conformation suitable for the cyclization, but that having a little lower tendency is not necessarily the case. The most stable conformer in monomer 1c was estimated using an AM1 calculation (Figure 4 (a)). ${ }^{14}$ This conformer has a " $\mathrm{g}^{-} \mathrm{g}^{+} \mathrm{g}^{-}$" form in the 1,4-diol skeleton, where the trans, clockwise, and counter-clockwise forms refer to as $\mathrm{t}, \mathrm{g}^{+}$, and $\mathrm{g}^{-}$, respectively. The dihedral angle between two benzoate groups is $-116^{\circ}$. The conformer has a negative chirality which is consistent with the result of the CD spectrum of monomer 1c. The vinyl groups in the conformer, however, are too apart for the intramolecular cyclization. Monomer 1c, therefore, has to change its conformation to be suited to the cyclization. As shown in Figure 4 (b), the most suitable conformer has a dihedral angle of $+30^{\circ}$ and the conformer has a " $\mathrm{g}^{+} \mathrm{g}^{+} \mathrm{g}^{-}$" form. The low population of the conformer results in the low tendency of cyclization for monomer 1c. The conformer having a positive chirality leads to form polymer $3 \mathbf{c}$ with a negative chirality, namely the main chain with an $R, R$-configuration, as a general rule. 


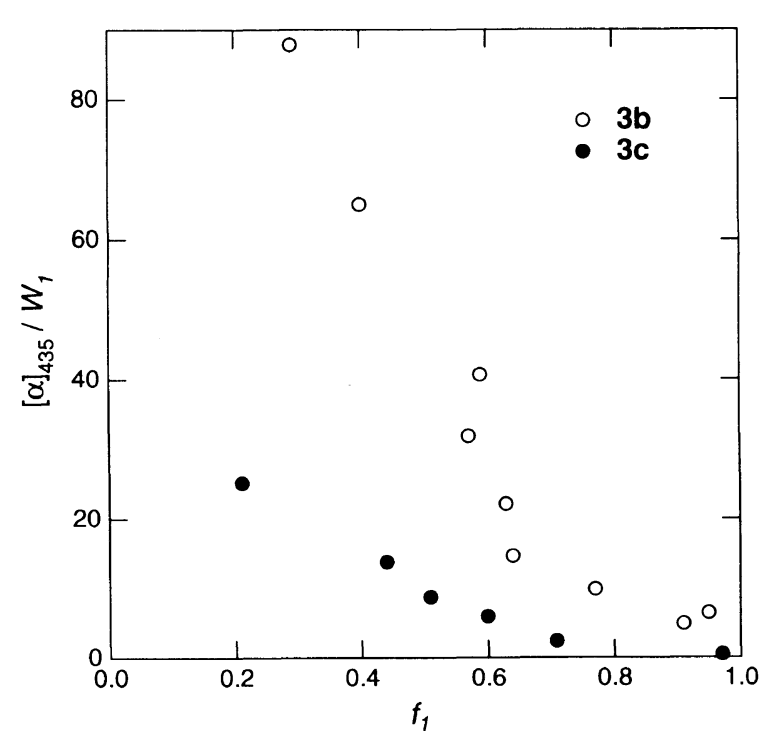

Figure 5. Absolute value of specific rotation $\left([\alpha]_{435}^{25}, c 1.0, \mathrm{CHCl}_{3}\right)$ of copolymer 3 divided by the weight fraction of $M_{1}$ units in copolymer $2\left(W_{1}\right)$ versus mole fraction of monomer 1 in copolymer 2.

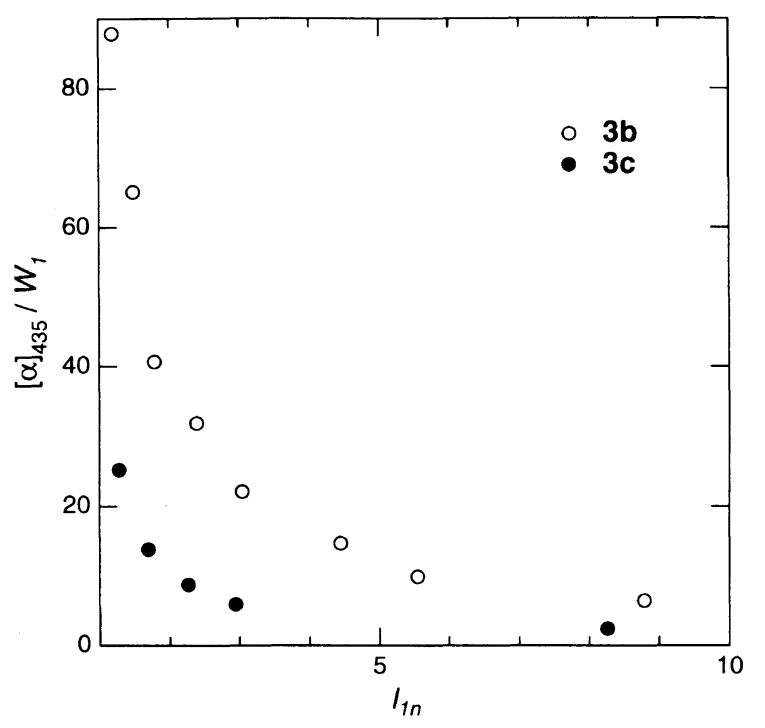

Figure 6. Absolute value of specific rotation $\left([\alpha]_{435}^{25}, c 1.0, \mathrm{CHCl}_{3}\right)$ of copolymer 3 divided by the weight fraction of $\mathrm{M}_{1}$ units in copolymer 2 $\left(W_{1}\right)$ versus the number-average length of monomer 1 runs $\left(l_{1 n}\right)$ in copolymer $\mathbf{2}$ calculated from the copolymerization parameters.

\section{Structural Effect of Chiral Template}

For polymers $\mathbf{3 b}$ and $\mathbf{3 c}$, the optical rotation value divided by the weight fraction of $\mathrm{M}_{1}$ units $\left([\alpha] / W_{1}\right)$, which means the average specific rotation of each benzoate diad, is shown as a function of the mole fraction of $M_{1}$ in Figure 5. The benzoate diad derived from the cyclic units effectively induce chirality when $\mathrm{M}_{2}$ units are present as a spacer. The number-average length of the $\mathrm{M}_{1}$ unit runs $\left(l_{1 n}\right),{ }^{15}$ therefore, was estimated from the copolymerization parameter, $r_{1}$. The $[\alpha] / W_{1}$ value increases when the $l_{1 n}$ value is close to 1.0 , as shown in Figure 6 . The isolated benzoate diad clearly becomes a source for the appearance of chirality in polymer 3 . The weight fraction of the isolated dibenzoate diad $\left[P\left(1, \mathrm{M}_{1}\right)\right]^{15}$ was calculated from the copolymerization parameter as well. Figure 7 shows that the plots of the $[\alpha]$ value vs. $P\left(1, \mathrm{M}_{1}\right)$ are indeed linear for polymers $\mathbf{3 b}$

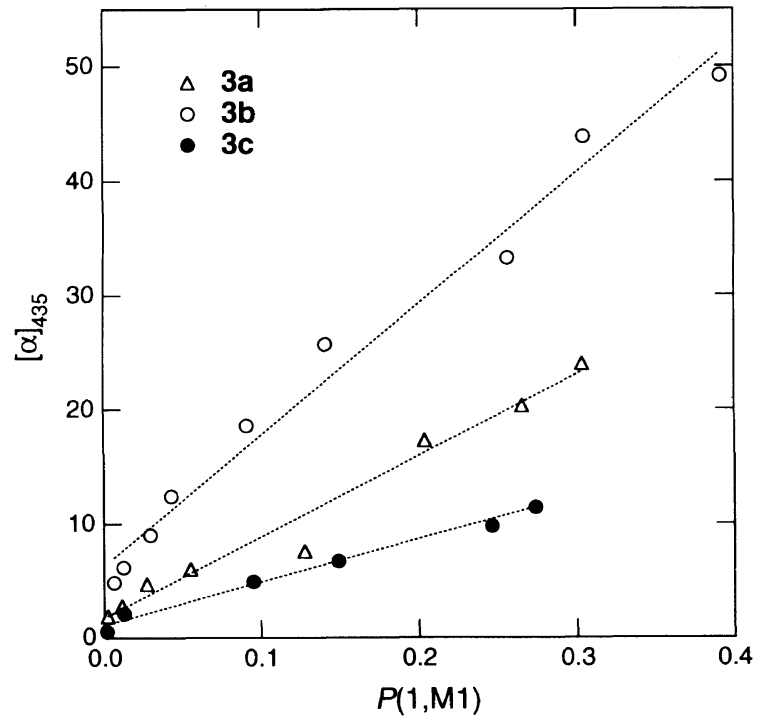

Figure 7. Absolute value of specific rotation $\left([\alpha]_{435}^{25}, c \quad 1.0, \mathrm{CHCl}_{3}\right)$ of copolymer 3 versus $P\left(1, \mathrm{M}_{1}\right)$.

and $\mathbf{3 c}$ along with 3a. The slope corresponds to an efficiency of template on the chiality induction. The efficiency decreased in the order of $\mathbf{b}>\mathbf{a}>\mathbf{c}$. The efficiency of the simple acyclic templates with two chiral centers, $\mathbf{d}, \mathbf{e}$, and $\mathbf{f}$ is the same order as that of the corresponding templates with one center, $\mathbf{g}, \mathbf{h}$, and $\mathbf{i}$, and is as follows: 1,3-diol > 1,4-diol > 1,2-diol. ${ }^{7}$ The mannitol templates $\mathbf{a}$, $\mathbf{b}$, and $\mathbf{c}$ correspond to the acyclic templates $\mathbf{d}, \mathbf{e}$, and $\mathbf{i}$, respectively. The decreasing order of efficiency in all the templates is as follows: $\mathbf{e}>\mathbf{b}>\mathbf{h}>\mathbf{f}>\mathbf{a}>\mathbf{c}>\mathbf{d} \geq \mathbf{i}>\mathbf{g}$. The efficiency is lower for template $\mathbf{b}$ than for template $\mathbf{e}$, though being higher for templates $\mathbf{a}$ and $\mathbf{c}$ than templates $\mathbf{d}$ and $\mathbf{i}$, respectively. Although polymer $\mathbf{2 d}$ contained a small amount of residual double bonds, the vinyl groups disappeared completely in polymer $\mathbf{2 a}$, thus suggesting that monomer 1a polymerized with complete cyclization. In the most suitable conformer, the dihedral angles between two benzoate groups are $8^{\circ}$ and $77^{\circ}$ for monomers 1a and 1d, respectively. Steric crowding by two dioxolane moieties produced a positive effect on the cyclization of monomer 1a, which retards inversion in the chiral face with regard to the ester carbonyl groups in the monomer. Because the direction of the ester carbonyl groups in the monomer seriously affected the chirality induction, the efficiency of chirality induction for template a was larger than that for template d. The presence of two dioxolane moieties in monomer $1 \mathrm{c}$ caused an increase in its cyclization tendency, in comparison with that for monomer 1i, as well. Because a wide distribution of conformers lowered the chirality induction efficiency of 1,4-diol template, the rotational barrier due to the dioxolane moiety especially at the carbons of C-4,5 produced a positive effect on the efficiency of template c. Monomer 1e giving the major conformer with a " $\mathrm{g}^{+} \mathrm{g}^{-}$" form in the 1,3-diol skeleton, which corresponds to a " $\mathrm{tg}$ " " form in the carbon skeleton, produced the highest efficiency of chirality induction. The presence of dioxane moiety at the carbon of C-4,6 in template $\mathbf{b}$, however, brings a negative effect for the most suitable conformation in the 1,3-diol template, thus lowering the efficiency of chirality induction.

Polym. J., Vol. 31, No. 4, 1999 


\section{CONCLUSIONS}

The chirality of polymer $\mathbf{3}$ is generally opposite to that of monomer 1 on their CD spectra. Although polymers 3a and $\mathbf{3 b}$ fell under the category, the chirality of polymer $3 \mathbf{c}$ was the same as that of monomer 1c. The conformer of monomer 1c suitable for cyclization was different in chirality from the most stable conformer. The efficiency of template on the chirality induction was estimated from the slope in the plots of the $[\alpha]$ value vs. $\left[P\left(1, \mathrm{M}_{1}\right)\right]$ for polymers 3a, b, and c. The efficiency decreased in the order of $\mathbf{b}>\mathbf{a}>\mathbf{c}$. The efficiency is lower for template $\mathbf{b}$ than the corresponding acyclic template e, though being higher for templates $\mathbf{a}$ and $\mathbf{c}$ than the acyclic templates d and $\mathbf{i}$, respectively. The presence of dioxolane moiety in templates a and $\mathbf{c}$ brought a positive effect for the most suitable conformation in the 1,2- and 1,4-diol templates, but that of dioxane moiety brought a negative effect in the 1,3-diol template. The diols a-c derived from D-mannitol, which is a relatively inexpensive source of chirality, were useful as the template for chirality induction in the cyclocopolymerizations of bis(4-vinylbenzoate) monomers (1a, 1b, and 1c) with styrene.

\section{REFERENCES AND NOTES}

1. (a) Y. Okamoto and T. Nakano, Chem. Rev., 94, 349 (1994). (b) K. Yokota, O. Haba, T. Satoh, and T. Kakuchi, Macromol. Chem. Phys., 196, 2383 (1995).
2. (a) G. Wulff, Angew. Chem. Int. Ed. Engl., 28, 21 (1989). (b) G. Wulff, R. Kemmerer, and B. Vogt, J. Am. Chem. Soc., 109, 7449 (1987).

3. T. Kakuchi, O. Haba, N. Fukui, T. Uesaka, M. Obata, and K. Yokota, Polymer, 37, 5703 (1996).

4. T. Kakuchi, O. Haba, E. Hamaya, T. Naka, T. Uesaka, and K. Yokota, Macromolecules, 29, 3807 (1996).

5. T. Kakuchi, O. Haba, N. Fukui, and K. Yokota, Macromolecules, 28, 5941 (1995).

6. (a) K. Nakanishi, N. Berova, and R. W. Woody, "Circular Dichroism-Principles and Applications," VCH Publishers Inc., New York, N.Y., 1994, p 361. (b) N. Harada and K. Nakanishi, "Circular Dichroic Spectroscopy-Exciton Coupling in Organic Stereochemistry," Mill Valley, CA, and Oxford University Press, Oxford, 1983.

7. (a) K. Yokota, T. Kakuchi, T. Uesaka, and M. Obata, Acta Polymer., 48, 459 (1997). (b) T. Kakuchi, T. Uesaka, M. Obata and K. Yokota, Kobunshi Ronbunshu, 54, 684 (1997).

8. M. Obata, T. Uesaka, K. Yokota, and T. Kakuchi, Macromolecules, 31, 4403 (1998).

9. T. Uesaka, E. Hamaya, O. Haba, T. Kakuchi, and K. Yokota, Enantiomer, 2, 215 (1997)

10. J. Kuszmann, É. Tomori, and P. Dvortsák, Carbohydr. Res., 132, 178 (1984).

11. A. Hirao, Y. Ishino, and S. Nakahama, Macromolecules, 21, 561 (1988).

12. T. H. Boer and H. J. Backer, Org. Syn. Coll., IV, 250 (1963).

13. F. Tüdös, T. Kelen, T. Földes-Berezsnich, and B. Turcsányi, J. Macromol. Sci.-Chem., A10, 1513 (1976)

14. The AMl calculations were carried out using the Mac SPARTAN Plus (Wavefunction, Inc.) program.

15. K. Ito and Y. Yamashita, J. Polym. Sci., Part A, Polym. Chem., 3, 2165 (1965). 